\title{
Vibration characteristics and equivalent Young's modulus of the Northern Library and the main tower, Bayon, Cambodia
}

\author{
T. Maeda ${ }^{1}$, T. Yamamoto ${ }^{1}$, Y. Wako ${ }^{2} \&$ T. Hirai $^{3}$ \\ ${ }^{1}$ Department of Architecture, Waseda University, Japan \\ ${ }^{2}$ Hazama Corporation, Japan \\ ${ }^{3}$ Obayashi Corporation, Japan
}

\begin{abstract}
We have studied vibration characteristics of the main tower and the sub-towers in the Bayon temple since 2003 and have found that the continuum equivalent Young's modulus for these tower-like dry-masonry structures is $1 / 10$ to $1 / 20$ of the typical value for the constituent rock blocks. In 2006, we measured microtremors at the Northern Library and the Southern Library in the Bayon temple. They are relatively small structures compared to the towers. Unlike those towers, they look like frame structures composed of columns, beams, and walls made of sandstone. Simulating their predominant frequencies by FEM, we found that the equivalent Young's modulus was similar to that for the towers and thus concluded that the reduced modulus $1 / 10$ to $1 / 20$ uniformly holds for the different types of dry-masonry structures in the Bayon temple. The Northern Library had been completely restored by 2004 and the Southern Library was to be restored. These libraries have similar predominant frequencies and there must not have been large influence of restoration on the vibration characteristics. The FEM model for the main tower in 2003 was based on photos and figures with speculation of the interior of the tower. In 2006 we had a chance to refer to the three-dimensional topographic data of the exterior and interior of the main tower obtained by laser type equipment. We refined the FEM model and simulated predominant frequencies again to find that the reduced equivalent modulus is still valid.

Keywords: Bayon temple, micro-tremor observation, vibration characteristics, FEM modelling, simulation of elastic modulus.
\end{abstract}




\section{Introduction}

Bayon temple, Cambodia, built in late 12th century to early 13 th century, is a dry-masonry temple made of sandstone being deteriorated possibly due to rain, plant intrusion, settlements, and so on. Strong wind blowing more than $20 \mathrm{~m} / \mathrm{s}$ was observed in the rainy season [1], which may cause vibration of the structure either directly or via ground motion; we may add wind induced vibration in the list of deterioration causes. The temple consists of a main tower, surrounding sub-towers, as well as two libraries at the northeast and the southeast as shown in fig. 1 [2]. The main tower is located at the top of man-made mound of about $15 \mathrm{~m}$ high as shown in fig. 1. Sub-towers stand from several different levels interconnected via the first and the second corridors. The libraries are located between the first and the second corridors.

We have studied vibration characteristics of the main tower and sub-towers by micro-tremor measurements in 2003 and 2004 [3], which can be regarded as a preliminary study for construction of analytical models toward wind response simulation, e.g. equivalent continuum models by FEM or discontinuous block modelling by DDA (Discontinuous deformation analysis). We found these tower-like dry-masonry structures do have vibration modes similar to continuous structure, e.g. reinforced concrete buildings, and damping factors of 2 to $3 \%$ and predominant frequencies of $3 \mathrm{~Hz}$ to $6 \mathrm{~Hz}$ according to their heights.

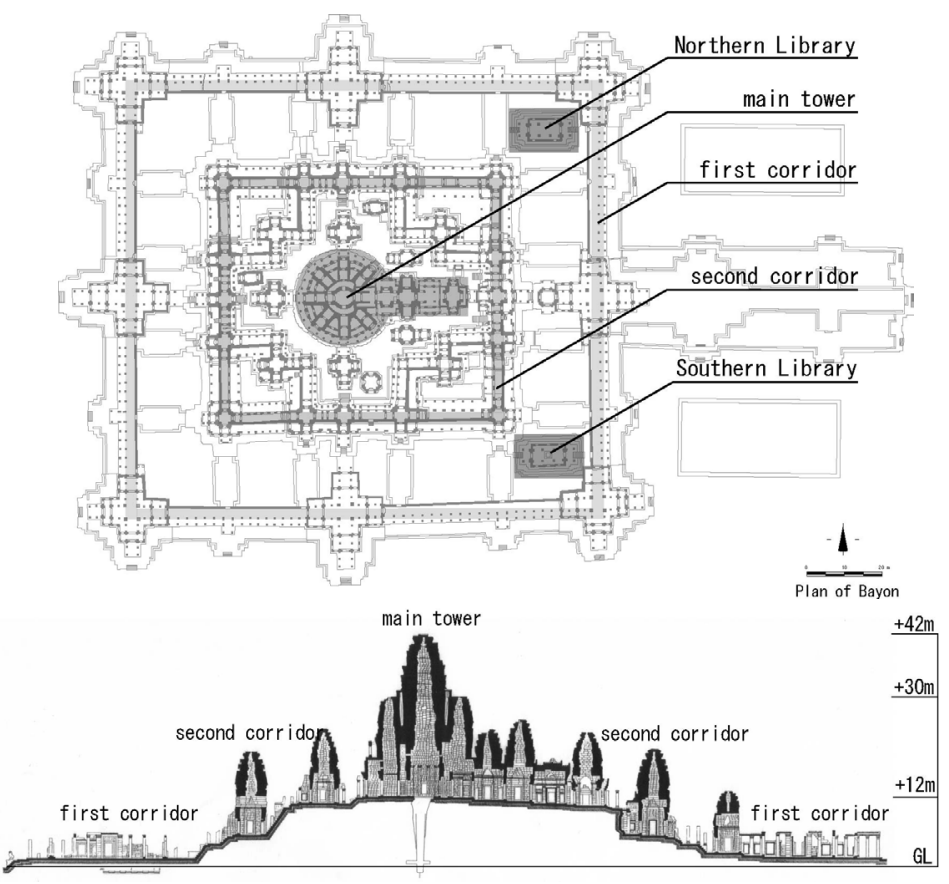

Figure 1: $\quad$ Site plan and section of the Bayon temple. 
Equivalent continuum models of FEM were constructed by simulating basefixed predominant frequencies in horizontal motion with varied elastic constants. With typical mass density and Poisson's ratio for sandstone, the equivalent Young's modulus is $1 / 10$ to $1 / 20$ of the typical value for sandstone.

In 2006, we measured micro-tremor at the Northern Library and the Southern Library. The Northern Library had been completely restored by 2004; it was dismantled and most of original sandstone blocks were set in the proper positions again with some new blocks replacing those severely deteriorated ones. The Southern Library is now under restoration and the measurement was done just before the restoration started. These libraries are relatively small structures compared to the towers, each covering the area of $6.6 \mathrm{~m}$ times $14.4 \mathrm{~m}$ with height of $4.1 \mathrm{~m}$. They consist of columns, beams, and walls made of sandstone and have a different structural system compared to the towers. By FEM simulation on the predominant frequencies of libraries, we could find the equivalent Young's modulus in accordance with that of the towers. Thus we have come to the conclusion that we can deal with dry-masonry sandstone structures in Bayon temple with the continuum equivalent Young's modulus regardless of structure types.

The FEM model for the main tower constructed in 2003 was based on photos and figures with speculation on the interior of the tower. In 2006, with the courtesy of the topographic survey team of JSA, we could refer to the threedimensional topographic data of exterior and interior of the tower obtained by laser type equipment. The refined FEM model strengthened confidence in our conclusion of the equivalent modulus.

\section{Structure of libraries}

The structures of the Northern Library and the Southern Library are basically the same. Details are well understood for the Northern Library, since it was entirely dismantled for restoration. We will review the basic structural feature of the Northern Library based on the JSA report [4].

The superstructure is a frame-like dry-masonry structure consists of columns, beams, and walls made of sandstone blocks as shown in fig. 2. It has eight interior columns in two rows of the north and the south of the centre line, dividing inner aisle and outer aisles. It also has four outer columns constituting the east and the west porches. These columns are made up of about ten sandstone blocks piled up vertically with no bondage. Beams are connecting column capitals mainly in longer side, east-west direction. They are made of sandstone of one span length, supporting corbel roof structure extended from the walls at the north and the south. The central aisle was supposed to be covered by a roof in the original form, but now it is missing. Walls are also made of sandstone blocks simply piled up without any mechanical devices.

The superstructures are supported by the platform of about $5 \mathrm{~m}$ high as shown in fig. 2. Pillars and walls stand on the sandstone pavement at the top of the platform, which is made of compacted soil layers doubly covered by laterite and sandstone blocks at the top and at the sides. 

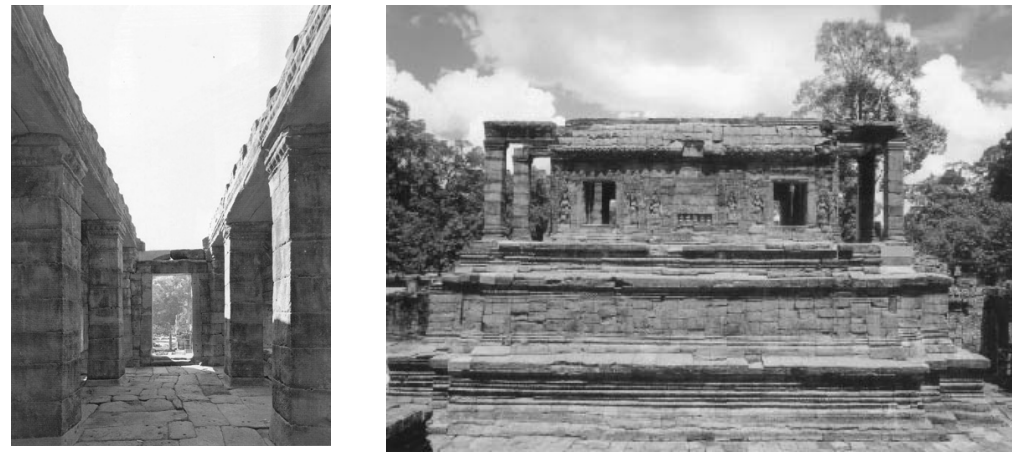

Figure 2: Interior and exterior views of the Northern Library.

\section{Micro-tremor measurements of Libraries}

\subsection{Sensor arrangements}

We used portable battery-operated three-component seismograph GPL-6A3P made by Akashi, which contains over-damped velocity meters and data logger and can be used with external sensors of the same specifications. Acceleration is acquired from the differentiated over-damped pendulum motion with frequency range of $0.1 \mathrm{~Hz}$ to $100 \mathrm{~Hz}$ and sensitivity of $1 \mathrm{mV} /$ gal. Twenty minutes of sensor outputs were low-pass filtered at $30 \mathrm{~Hz}$ and amplified by 1000 times, then discretized by 20 bit AD converter with $100 \mathrm{~Hz}$ sampling. Fifty to one hundred samples of 20.48 seconds are selected from twenty minute data and ensemble averaged for power spectrum estimation. We configured several sensor arrangements to acquire vibration characteristics of horizontal translations, vertical translation, rocking, and torsion as shown in fig. 3. Similar arrangements were configured for the Southern Library.

\subsection{Vibration characteristics}

Fig. 4 shows power spectra for NS components of the Northern Library revealing predominant frequency of $5.6 \mathrm{~Hz}$; band-pass filtered time history at $5.6 \mathrm{~Hz}$ shows in-phase motion with relative dominance at the north and south edges. Fig. 5 shows transfer function of the roof level to the floor level; out-of-phase motion is observed at $5.8 \mathrm{~Hz}$, which is considered as base-fixed natural frequency for the NS horizontal $1^{\text {st }}$ mode. Fig. 7 shows power spectra for EW components of the Northern Library. Predominant frequency is not easy to indicate; however, band-pass filtered time history at $8.3 \mathrm{~Hz}$ only shows in-phase motion among peaks. Transfer function shown in fig. 8 with out-of phase characteristics at $9.4 \mathrm{~Hz}$ supports the predominant frequency of $8.3 \mathrm{~Hz}$ for the EW horizontal $1^{\text {st }}$ mode. Based on similar studies for the Southern Library, soil-coupled predominant frequency is $4.7 \mathrm{~Hz}$ and base-fixed natural frequency is $4.8 \mathrm{~Hz}$ for NS horizontal $1^{\text {st }}$ mode; $9.0 \mathrm{~Hz}$ and $9.2 \mathrm{~Hz}$ are for $\mathrm{EW}$ horizontal $1^{\text {st }}$ mode, respectively. 

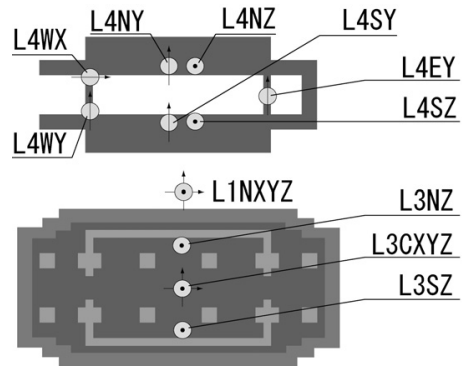

(a) NS translation

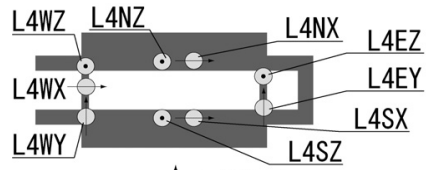

$\stackrel{\odot}{\odot}$ LINXYZ

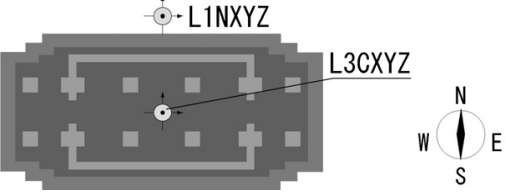

(c) UD translation and torsion

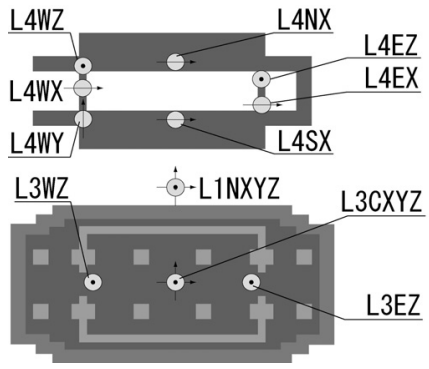

(b) EW translation
L4: Beam level

L3: Floor level

$\mathrm{X}$ : Eastward positive

Y: Northward positive

Z: Upward positive

Figure 3: $\quad$ Sensor arrangements for the Northern Library.
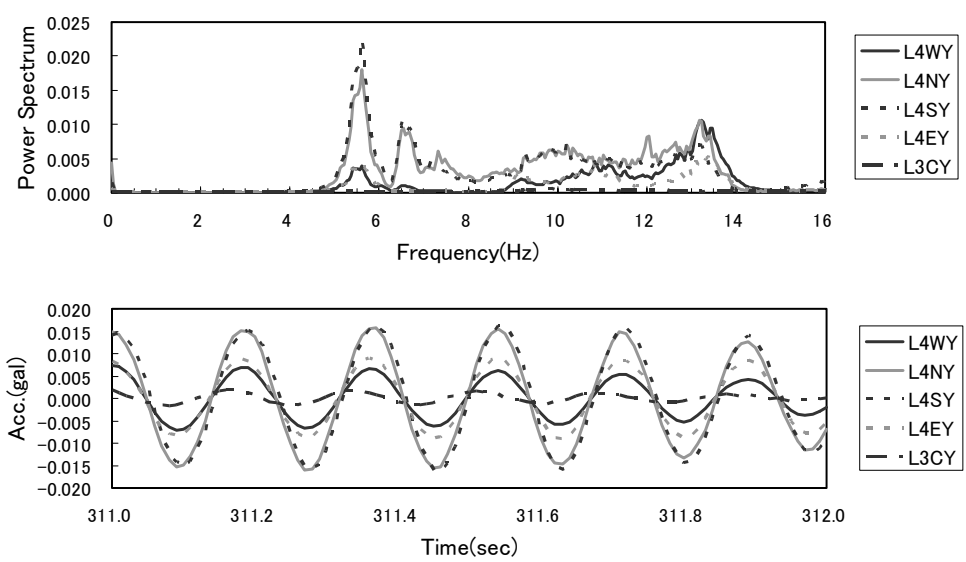

Figure 4: $\quad$ Power spectrum and band-pass filtered time history at $5.6 \mathrm{~Hz}$ for NS translation of the Northern Library. 
498 Structural Studies, Repairs and Maintenance of Heritage Architecture X
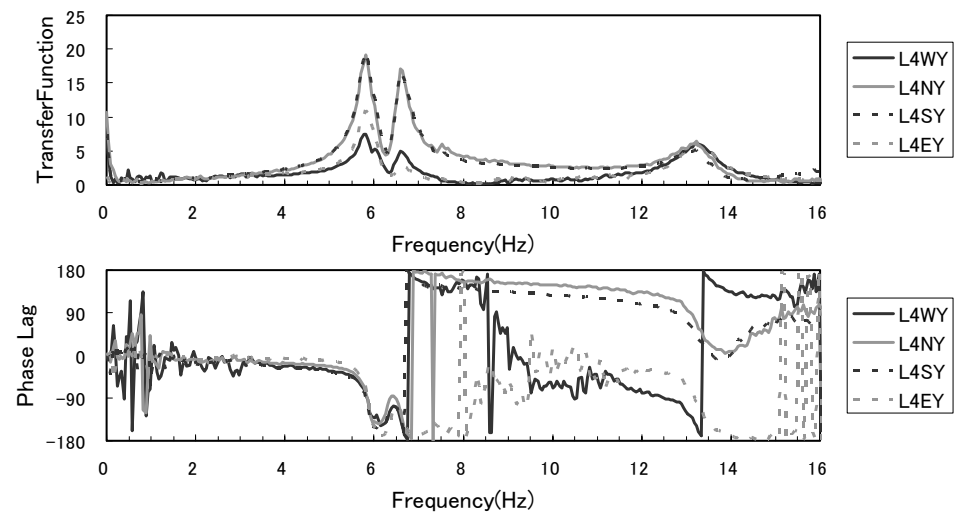

Figure 5: Transfer function for NS translation of the Northern Library.
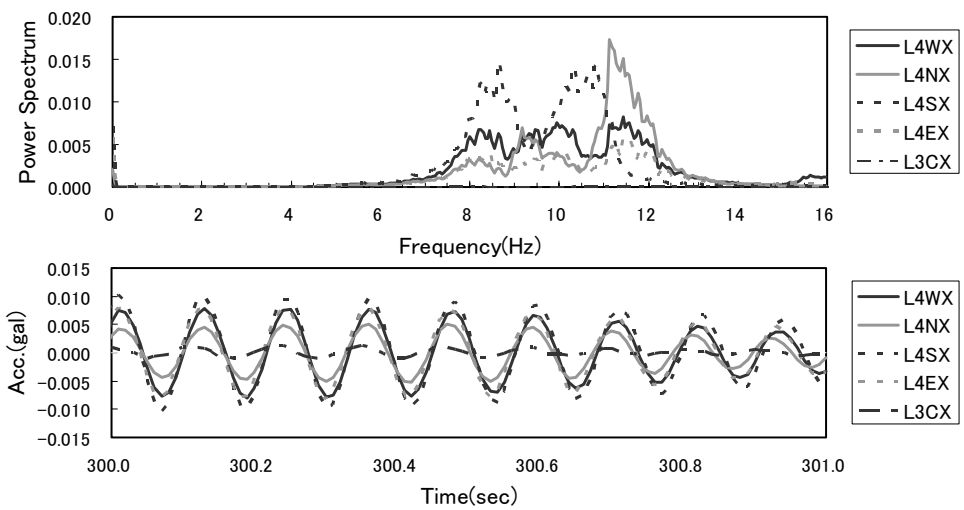

Figure 6: $\quad$ Power spectrum and band-pass filtered time history at $8.3 \mathrm{~Hz}$ for EW translation of the Northern Library.
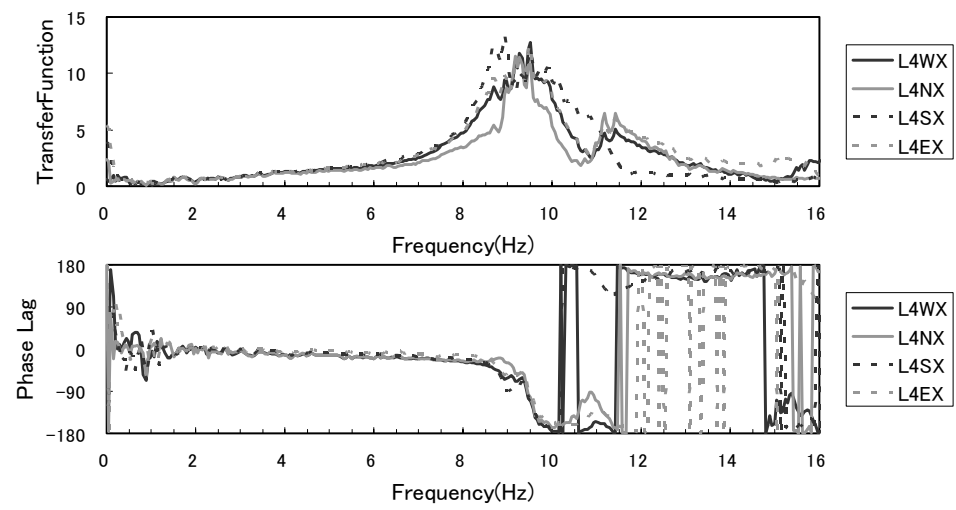

Figure 7: Transfer function for EW translation of the Northern Library. 
From these figures, NS translation is the most recognizable mode for both libraries with relative dominance at the north and south edges. We attempted to evaluate rocking motion and torsion by processing the data, but it was not easy to indicate predominant frequencies with proper phase relations. For vertical motion, transfer function is almost unity up to $16 \mathrm{~Hz}$, and we can conclude that the vertical $1^{\text {st }}$ mode lies beyond $16 \mathrm{~Hz}$. The summary of the predominant frequencies are shown in table 1. Predominant frequencies are similar for the same modes of the libraries and we assume that the restoration of the Northern Library did not influence much on the vibration characteristics.

Table 1: Summary of predominant frequencies and base-fixed natural frequencies. (The latter shown in the parentheses.)

\begin{tabular}{|c|c|c|}
\hline Mode & Northern Library [Hz] & Southern Library [Hz] \\
\hline NS translation & $5.6(5.8)$ & $4.7(4.8)$ \\
\hline EW translation & $8.3(9.4)$ & $9.0(9.2)$ \\
\hline
\end{tabular}

\section{FEM modelling of the Libraries}

\subsection{FEM models}

Similar to the study on the main tower and sub-towers [3], we have constructed FEM model for the Northern Library and the Southern Library by simulating the base-fixed natural frequencies in horizontal motion. The model for the Northern Library is shown in fig. 8. The differences in the Southern Library are window arrangements and partial lack of porches. The model for the Northern Library has 7,968 nodes and 4,891 elements with total mass of 206 ton and for the Southern Library, 6,582 nodes and 3,822 elements of total mass of 163 ton.

Referring to the laboratory test done by Prof. Koshiishi of Waseda University, newly quarried sandstone sample from Angkor area has the averaged elastic property summarized in table 2. We varied Young's modulus to simulate the frequencies, while retaining Poisson's ratio and mass density in the table.
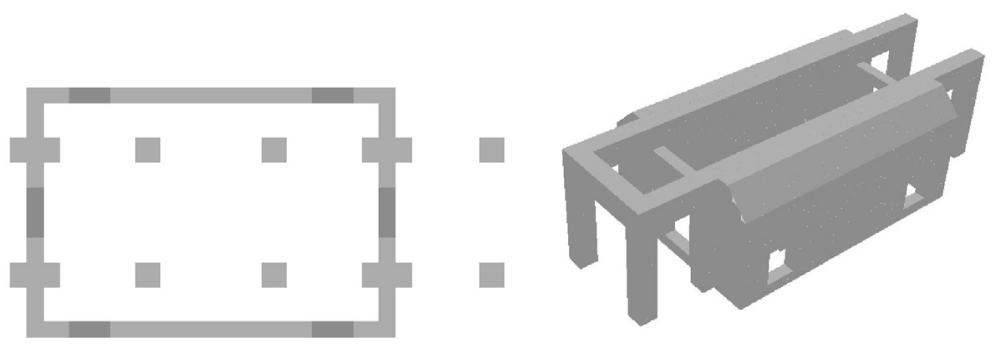

Figure 8: $\quad$ FEM model for the Northern Library. 
Table 2: $\quad$ Property of Sandstone and Laterite.

\begin{tabular}{|c|c|c|c|}
\hline & $\begin{array}{c}\text { Young's } \\
\text { modulus } \\
{\left[\mathrm{N} / \mathrm{mm}^{2}\right]}\end{array}$ & Poisson's ratio & $\begin{array}{c}\text { Mass density } \\
{\left[\mathrm{g} / \mathrm{cm}^{3}\right]}\end{array}$ \\
\hline Sandstone & 13,000 & 0.11 & 2.52 \\
\hline Latrite & 20,000 & 0.25 & 2.01 \\
\hline
\end{tabular}

\subsection{Equivalent modulus}

The base-fixed natural frequencies from the micro-tremor measurements and FEM analyses are compared in table 3 with the adjusted Young's modulus of $850 \mathrm{~N} / \mathrm{mm}^{2}$., which is about $1 / 15$ of the sandstone itself shown in table 2 . In the table 3, vertical translation mode and torsion mode are also included for comparison, though it is not clear as those for horizontal translations. With that reduced Young's modulus, analytically obtained natural frequencies are consistent with the measured ones for each component.

In fig. 9, analytically obtained horizontal translation modes of the Northern Library are shown for NS and EW translations. The NS translation mode depicts relative dominance at the north and the south edges to the other edges as the measurement suggested. For the Southern Library, the adjusted Young's modulus is $480 \mathrm{~N} / \mathrm{mm}^{2}, 1 / 27$ of the sandstone's Young's modulus. Comparison of base-fixed natural frequencies is shown in table 3. We will have to improve our models to resolve the difference in Young's modulus with further reference to the coming report of JSA on the restoration of the Southern Library.

Table 3: $\quad$ Comparison of base-fixed natural frequencies of libraries.

\begin{tabular}{|c|c|c|c|c|}
\hline$[\mathrm{Hz}]$ & \multicolumn{2}{|c|}{ Northern Library } & \multicolumn{2}{c|}{ Southern Library } \\
\hline Mode & Analysis & Measure & Analysis & Measure \\
\hline NS translation & 5.8 & 5.8 & 4.7 & 4.7 \\
\hline EW translation & 10.3 & 9.4 & 8.2 & 9.0 \\
\hline UD translation & 17.8 & $>16$ & 15.2 & $>16$ \\
\hline Torsion & 12.9 & 11.1 & 9.8 & 10.0 \\
\hline
\end{tabular}

\section{FEM remodelling of the main tower}

The main tower is a sandstone dry-masonry structure of about $30 \mathrm{~m}$ high and base radius of about $5.5 \mathrm{~m}$. It consists of the central tower, attached eight subtowers interconnected by the gallery. Our 2003 FEM model has 1,583 nodes, 3,379 elements of total mass of 5,986 ton with the equivalent Young's modulus of $1,200 \mathrm{~N} / \mathrm{mm}^{2}$. Our 2006 FEM model is based on the three dimensional topographic data [5] shown in fig. 10, which has 7,884 nodes, 4,777 elements of total mass of 8,389 ton with the equivalent modulus of $1,500 \mathrm{~N} / \mathrm{mm}^{2}$. The large difference of total mass comes mostly from revised wall thicknesses, which was uncertain in 2003 and 2004. Comparison of the models is shown in fig. 11. 

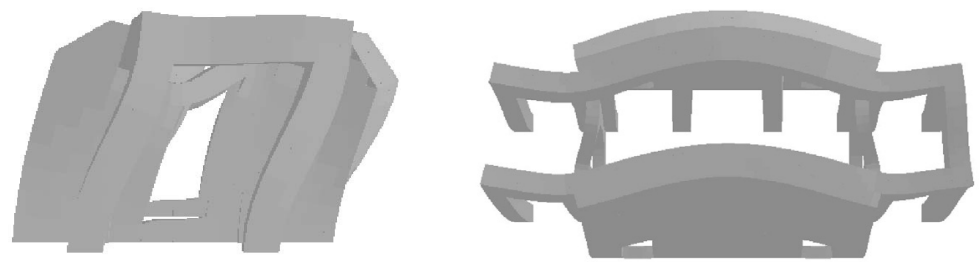

(a) NS horizontal $1^{\text {st }}$ mode.
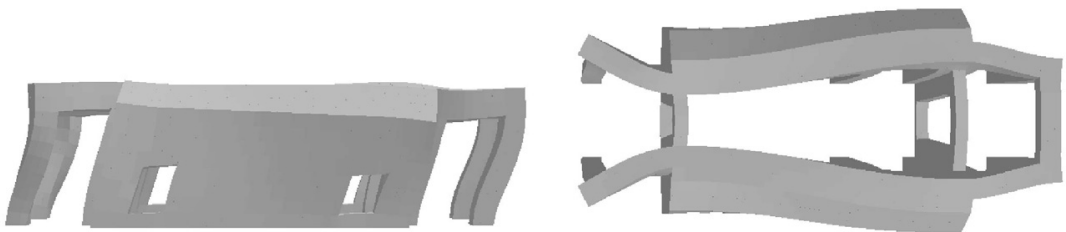

(b) EW horizontal $1^{\text {st }}$ mode.

Figure 9: NS and EW translational modes of the Northern Library FEM model.
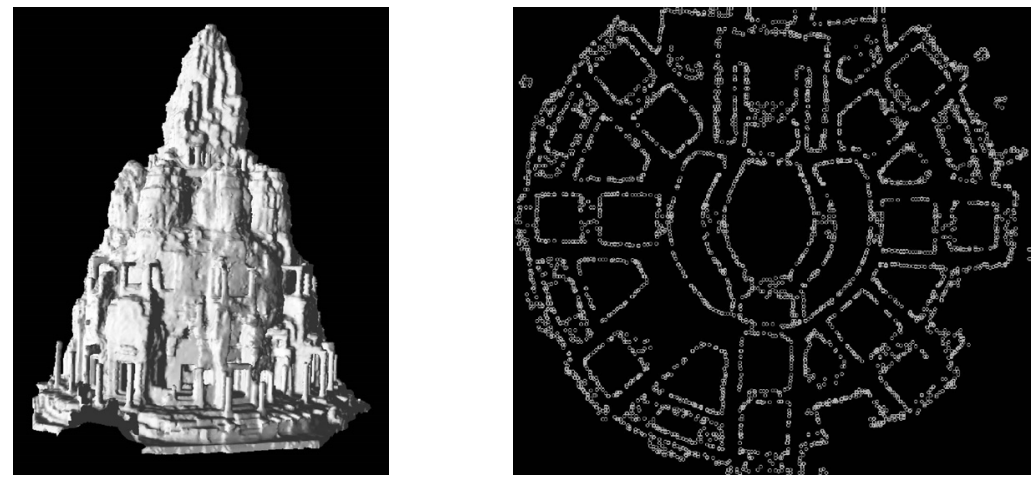

Figure 10: Three dimensional topographic data of the main tower.

\section{Conclusions}

We have been studying vibration characteristics of the dry-masonry structures in the Bayon temple, Angkor, Cambodia. In 2005, we revised our 2003 main tower FEM model with newly obtained three dimensional topography data, especially in terms of wall thickness to find $25 \%$ increase in the equivalent modulus. We also evaluated continuum equivalent Young's modulus for the Northern Library and the Southern Library, which are frame-like sandstone dry-masonry structures of columns, beams, and walls. Despite the fact that their structures are very much different from the towers, the equivalent Young's moduli are not far from those 
for the towers. Thus we conclude that the equivalent continuum Young's modulus is about $1 / 10$ to $1 / 20$ of that for the constituent rock regardless of the structure types.

We acknowledge JSA for their support on micro-tremor measurement, to Ikeuchi Laboratory of Tokyo University for three-dimensional topography data of the main tower, and to Prof. Koshiishi of Waseda University for laboratory test data of sandstone. This study is partially supported by Waseda University Grant for Special Research Projects 2006B-144.

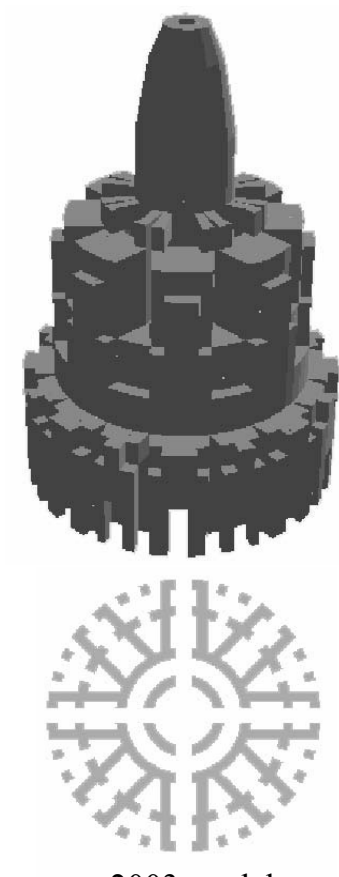

2003 model

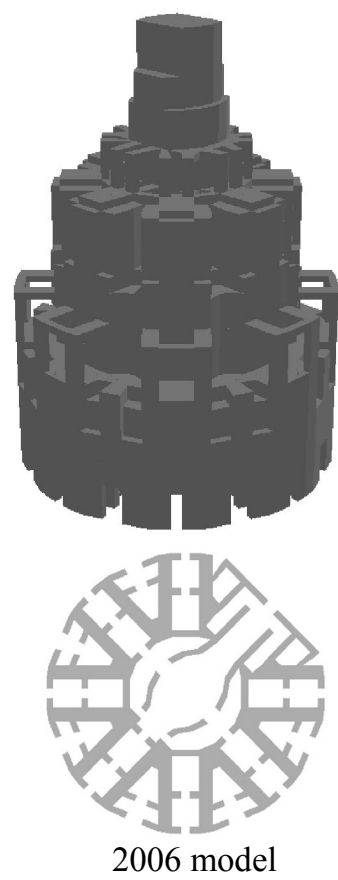

Figure 11: Comparison of FEM models for the main tower.

\section{References}

[1] JSA (Japanese Government Team for Safeguarding Angkor), Annual Report on the Technical Survey of Angkor Monument 1995.

[2] Dumarcay, J., Le Bayon, PEFEO, 1976.

[3] Maeda, T., Sugiura, Y. and Hirai, T., Vibration characteristics of the Bayon temple main tower, Angkor, Cambodia, STREMAH IX, 255-264, 2005.

[4] JSA, Report on the Conservation and Restoration Work of the Northern Library of Bayon, Angkor Thom, Kingdom of Cambodia, 2000. 
Structural Studies, Repairs and Maintenance of Heritage Architecture X 503

[5] Ikeuchi, K., Hasegawa K., Nakazawa A., Takamatsu J., Oishi, T. and Masuda, T., Bayon Digital Archival Project, 10th International Conference on Virtual Systems and Multimedia (VSMM2004), November 2004. 